\title{
Coordination mechanisms for inventory control in three-echelon serial and distribution systems
}

\author{
Henk Zijm • Judith Timmer
}

Published online: 28 September 2007

(C) Springer Science+Business Media, LLC 2007

\begin{abstract}
This paper is concerned with the coordination of inventory control in threeechelon serial and distribution systems under decentralized control. All installations in these supply chains track echelon inventories. Under decentralized control the installations will decide upon base stock levels that minimize their own inventory costs. In general these levels do not coincide with the optimal base stock levels in the global optimum of the chain under centralized control. Hence, the total cost under decentralized control is larger than under centralized control.

To remove this cost inefficiency, two simple coordination mechanisms are presented: one for serial systems and one for distribution systems. Both mechanisms are initiated by the most downstream installation(s). The upstream installation increases its base stock level while the downstream installation compensates the upstream one for the increase of costs and provides it with a part of its gain from coordination. It is shown that both coordination mechanisms result in the global optimum of the chain being the unique Nash equilibrium of the corresponding strategic game. Furthermore, all installations agree upon the use of these mechanisms because they result in lower costs per installation. The practical implementation of these mechanisms is discussed.
\end{abstract}

Keywords Supply chain · Inventory control · Strategic game $\cdot$ Nash equilibrium · Multi-echelon system $\cdot$ Coordination mechanism

\section{Introduction}

This paper is concerned with the coordination of inventory control in three-echelon serial and distribution systems under decentralized control. All installations in these supply chains track echelon inventories. Under decentralized control an installation will decide upon a

H. Zijm · J. Timmer $(\bowtie)$

Stochastic Operations Research Group, Faculty of Electrical Engineering, Mathematics and Computer Science, University of Twente, P.O. Box 217, 7500 AE Enschede, The Netherlands

e-mail: j.b.timmer@utwente.nl 
base stock level that minimizes its individual inventory cost. Hence, the system consists of selfish installations and it is therefore not surprising that in general their decisions are not optimal from the perspective of the supply chain as a whole. That is, the total cost of the system under decentralized control is larger than in the supply chain optimum.

To improve upon this cost inefficiency asks for some coordination between the installations. While maintaining decentralized decision-making, the goal of a coordination mechanism is to change the structure of the installations' costs such that the individual decisions of the installations are optimal for the system as a whole, that is, they coincide with the optimal decisions under centralized control. In this paper game theory is used to show that our coordination mechanism indeed achieves this goal. Furthermore, the coordination mechanism should make each installation better off, that is, it should result in lower cost. Applying such a mechanism results in the total cost of the system being as low as possible. All firms should agree upon the use of a certain coordination mechanism; this can be achieved by negotiations between the installations.

The basic systems under consideration, three-echelon serial and distribution systems, are widely studied in the literature. The concept of echelon stock was introduced in Clark and Scarf (1960). They showed the value of echelon stock for integrated control of serial systems compared to local stock, as well as the optimality of inventory control by means of echelon base stock levels. Langenhoff and Zijm (1990) study multi-echelon production/distribution systems under centralized control. In case of a distribution system, the depot is allowed to keep stock. They derive optimal base stock policies for serial and distribution systems. A distribution system with a stockless depot (supplier) is considered in Eppen and Schrage (1981). For a review on multi-stage serial systems we refer to Van Houtum et al. (1996).

In case of both serial and distribution systems, the literature recognizes that decentralized control leads to larger total costs. Several papers study coordination mechanisms, mostly for distribution systems. A two-echelon serial supply chain is investigated by Cachon and Zipkin (1999). In that paper each installation may incur a consumer backorder penalty cost because the upper stage (supplier) is assumed to dislike backorders of his product at the retailer. Two noncooperative games are considered, based on whether local or echelon inventory is tracked. These games nearly always have a unique Nash equilibrium which differs from the global optimum. Under specific conditions the global optimum can be achieved, if local inventory is tracked, as a (possibly non-unique) Nash equilibrium by using a linear transfer payment.

Lee and Whang (1999) study a two-echelon serial supply chain under decentralized control where each party minimizes its discounted costs. They assume that all installations belong to a single organization. Under a so-called performance measurement scheme, which is based on three basic properties, the installations minimize their discounted costs by selecting the global optimal outcome. Our coordination mechanism, which is described below, also results in the installations choosing the global optimum but its starting points are different. First, in our model the installations minimize average costs and second, our mechanism is built on negotiations between the parties in combination with money transfers to share costs and gains. Besides, we show that each installation is better off with the mechanism than without it, which provides a sufficient basis for the mechanism to be accepted by all parties.

A distribution system with one supplier and $N$ retailers is studied in Cachon (2001). All firms pay inventory and backorder cost; the backorder cost for the supplier reflects the supplier's interest in the availability of his product at the retailers, as in Cachon and Zipkin (1999). A retailer continuously monitors his inventory and uses an $(r, q)$ ordering policy for replenishment: whenever his inventory position drops to $r$ he places an order for $q$ units. Demand for the product is Poisson distributed. The supplier serves the retailers on a firstcome-first-serve basis. It is shown that the competitive solution need not coincide with the 
global optimum. Three cooperation strategies are discussed, of which two lead to the global optimum being a Nash equilibrium.

The model of Cachon and Zipkin (1999) is extended by Wang et al. (2004) to a distribution system with 1 supplier and $n$ different retailers, each with its own lead time and holding cost. After studying the system under decentralized control, coordination mechanisms are examined. In case the firms track echelon inventories, a contract is presented in which the retailers pay a nonlinear tariff (a nonlinear function of the base stock level) to the supplier. This contract ensures that the system optimal solution is the unique Nash equilibrium of the game. Nevertheless, nonlinear tariffs are not easy to implement.

Other models of coordination of inventories in serial or distribution systems include Axsäter and Zhang (1999), Chen et al. (2001), Gjerdrum et al. (2002), Güllü et al. (2003), Özer (2003), Taylor (2002), and Viswanathan and Piplani (2001).

In this paper we present simple coordination mechanisms for three-echelon serial and distribution systems under the (natural) assumption that installations only communicate with their direct neighbors upstream and downstream in the supply chain. Further, all order decisions are based upon echelon inventory. As argued below, the coordination is such that the supplier (the installation upstream) increases his base stock level while the retailer (the installation downstream) compensates the supplier for the increase of costs. Besides, the retailer transfers a part of his gain from the coordination, his cost savings less the compensation paid, to the supplier. Both the mechanisms for serial and distribution systems result in the installations choosing the global optimal base stock levels. This choice of base stock levels is the unique Nash equilibrium of the corresponding strategic game played by the installations. Further, all agree upon the use of these mechanisms because they result in lower costs per installation. These results also hold for systems with more than three echelons.

Most authors in the literature study two-echelon systems because their qualitative results remain valid for multi-echelon systems. One of the exceptions is Giannoccaro and Pontrandolfo (2004), who study revenue-sharing contracts for three-echelon serial systems. These contracts are non-straightforward extensions of the contracts for two-echelon systems since the contracts have to be extended from a single two-firm contract to two two-firm contracts whose parameters are mutually dependent. In this paper we study three-echelon systems under decentralized control since our game-theoretic analysis also does not allow for a straightforward generalization of the results from two-echelon systems to three-echelon systems. This is due to the negotiation process in use: for two-echelon systems a single round of negotiations will do, while for three-echelon systems more rounds of negotiations are needed. This follows from the natural assumption that installations only communicate with their direct neighbors in the system and therefore the order of the negotiations matters.

Further, most coordination mechanisms in the literature are such that due to actions taken by the supplier (the installation upstream) the retailer (the installation downstream) is induced to adopt the globally optimal base stock level. Opposed to this, we show in Sect. 3 that decentralized control is most unfavorable for the retailer with regard to costs. Hence, using arguments from game theory, the retailer will initiate negotiations with the supplier with the goal of achieving a reduction in his costs. In the end the negotiations result in each installation selecting his globally optimal base stock level and in cost savings for all.

The outline of this paper is as follows. In the next section we briefly recall results of serial systems under centralized control. In Sect. 3 serial systems under decentralized control are studied. A coordination mechanism for these systems and its practical implementation are presented in Sect. 4. Distribution systems under decentralized control are analysed in Sect. 5, and a coordination mechanism for these systems, as well as its implementation, is presented in Sect. 6. Section 7 concludes. 


\section{Three-echelon serial systems under centralized control}

We start by studying inventory control for a single good in a three-echelon serial system. Such a system is a supply chain consisting of three installations in a series. The installations are numbered from 1, the most downstream installation, to 3. An echelon is a set of installations, starting from a certain installation and including all installations downstream. Echelons are numbered according to their most upstream installation. Hence, in the serial system under consideration, echelon $i$ includes the installations $i$ down to 1 .

Demand for the good occurs only at the most downstream installation, installation 1 . The distribution function of the $l$-period cumulative demand $u_{l}$ is denoted by $F_{l}$. If $l=1$ we write $F$ instead of $F_{1}$. Let $\mu$ denote the expected demand per period.

The installations determine the quantity of the orders for replenishment of their stock on the basis of their echelon inventory position. The echelon stock of an installation consists of all stock at that installation plus all stock in transit to or on hand at any installation downstream minus eventual backlogs at installation 1 . The echelon inventory position denotes the echelon stock plus materials that are already ordered but not yet delivered at the most upstream installation in the echelon.

All installations place their orders for replenishment of stock at the end of a period. A material shortage at installation 2 or 3 is possible, leading to incomplete fulfillment of the orders of installation 1 or 2 . Any excess demand is backlogged. The ordered goods are delivered after a fixed lead time. Namely, it takes $l_{3}$ periods to transfer materials from the outside supplier, who can always deliver, to installation 3 , and $l_{i}$ periods are needed to transfer materials from installation $i+1$ to installation $i, i=1,2$.

The holding costs for installation $i$ are $h_{i}+\cdots+h_{3}$ for goods at installation $i$ and, if $i>1$, for goods in transfer to installation $i-1$. Installation 1 pays a penalty cost $p$ for unfilled demand. All these costs are linear in time and quantity and occur at the end of a period.

In Langenhoff and Zijm (1990) a natural definition for the echelon cost functions of all installations is developed. We briefly repeat this. Let $x_{i}$ denote the echelon stock associated with installation $i$ at the beginning of a period before demand occurs. Assign the following one-period holding and penalty cost to installation 1 :

$$
L_{1}\left(x_{1}\right)=h_{1} \int_{0}^{\infty}\left(x_{1}-u\right) \mathrm{d} F(u)+\left(p+h_{1}+h_{2}+h_{3}\right) \int_{x_{1}}^{\infty}\left(u-x_{1}\right) \mathrm{d} F(u) .
$$

Further, assign

$$
L_{j}\left(x_{j}\right)=h_{j} \int_{0}^{\infty}\left(x_{j}-u\right) \mathrm{d} F(u)
$$

to installation $j, j=2,3$.

Let $D_{N}\left(y_{1}, \ldots, y_{N}\right)$ denote the average total cost of an $N$-echelon serial system if at the beginning of every period the echelon inventory position of echelon $i$ is increased by installation $i$ to $y_{i}$, where $y_{1} \leq y_{2} \leq \cdots \leq y_{N}$. As shown by Langenhoff and Zijm (1990) the cost $D_{N}$ is composed of $N$ terms

$$
D_{N}\left(y_{1}, \ldots, y_{N}\right)=C_{1}\left(y_{1}\right)+C_{2}\left(y_{1}, y_{2}\right)+\cdots+C_{N}\left(y_{1}, \ldots, y_{N}\right)
$$

where

$$
C_{1}\left(y_{1}\right)=\int_{0}^{\infty} L_{1}\left(y_{1}-u_{l_{1}}\right) \mathrm{d} F_{l_{1}}\left(u_{l_{1}}\right)
$$


and

$$
\begin{aligned}
& C_{j}\left(y_{1}, \ldots, y_{j}\right) \\
& =\int_{0}^{\infty} L_{j}\left(y_{j}-u_{l_{j}}\right) \mathrm{d} F_{l_{j}}\left(u_{l_{j}}\right) \\
& \quad+\int_{y_{j}-y_{j-1}}^{\infty}\left[C_{j-1}\left(y_{1}, \ldots, y_{j-2}, y_{j}-u_{l_{j}}\right)-C_{j-1}\left(y_{1}, \ldots, y_{j-2}, y_{j-1}\right)\right] \mathrm{d} F_{l_{j}}\left(u_{l_{j}}\right)
\end{aligned}
$$

for $j=2, \ldots, N$. In the expression for $C_{j}$ the second integral represents a penalty cost for installation $j$ if it cannot fulfill the order of installation $j-1$, that is, if $y_{j}-u_{l_{j}}<y_{j-1}$. In the next Lemma we show how the cost $D_{i}$ depends on $D_{i-1}$.

Lemma 2.1 The average cost of an $N$-echelon serial system, $N=1,2,3$, can be written as

$$
\begin{gathered}
D_{1}\left(y_{1}\right)=h_{1}\left(y_{1}-\left(l_{1}+1\right) \mu\right)+\left(p+h_{1}+h_{2}+h_{3}\right) \int_{y_{1}}^{\infty}\left(u_{l_{1}+1}-y_{1}\right) d F_{l_{1}+1}\left(u_{l_{1}+1}\right), \\
D_{2}\left(y_{1}, y_{2}\right)=D_{1}\left(y_{1}\right)+h_{2}\left(y_{2}-\left(l_{2}+1\right) \mu\right)+\int_{y_{2}-y_{1}}^{\infty}\left[D_{1}\left(y_{2}-u_{l_{2}}\right)-D_{1}\left(y_{1}\right)\right] d F_{l_{2}}\left(u_{l_{2}}\right),
\end{gathered}
$$

and

$$
\begin{aligned}
D_{3}\left(y_{1}, y_{2}, y_{3}\right)= & D_{2}\left(y_{1}, y_{2}\right)+h_{3}\left(y_{3}-\left(l_{3}+1\right) \mu\right) \\
& +\int_{y_{3}-y_{2}}^{\infty}\left[D_{2}\left(y_{1}, y_{3}-u_{l_{3}}\right)-D_{2}\left(y_{1}, y_{2}\right)\right] d F_{l_{3}}\left(u_{l_{3}}\right) .
\end{aligned}
$$

All proofs can be found in Sect. 8. This Lemma shows that the cost $D_{i}$ of echelon $i>1$ consist of the cost of echelon $i-1$ plus additional holding cost and a kind of penalty in case of a shortage, $y_{i}-u_{l_{i}}<y_{i-1}$. In Langenhoff and Zijm (1990) the minimum of $D_{3}\left(y_{1}, y_{2}, y_{3}\right)$ is found, which is repeated in the Lemma below.

Lemma 2.2 (Langenhoff and Zijm 1990) The cost function $D_{3}\left(y_{1}, y_{2}, y_{3}\right)$ is minimized in $\left(y_{1}, y_{2}, y_{3}\right)=\left(S_{1}, S_{2}, S_{3}\right)$ where $S_{1}$ minimizes $D_{1}\left(y_{1}\right), S_{2}$ minimizes $D_{2}\left(S_{1}, y_{2}\right)$ and $S_{3}$ minimizes $D_{3}\left(S_{1}, S_{2}, y_{3}\right)$.

To implement this optimal solution, centralized control is needed. But in practice, there is no centralized but decentralized control. Each installation acts on his own and independently decides about his base stock level $y_{i}$, which will be used in every period. This decision affects the costs of the other installations. A noncooperative strategic game (see Osborne and Rubinstein 1994) is a suitable tool for modeling and analysing such a situation since it can handle the strategic effects of the decisions on the costs of the other firms. In a strategic game each installation, or player, has to make one decision. These decisions are made independently and simultaneously. Further, a strategic game is described by a set of players and for each player a strategy set and a cost function. Here, the three installations are the players. The strategy set $Y_{i}$ of player $i$ is defined as the set of all possible echelon base stock levels. A triple of strategies $\left(y_{1}, y_{2}, y_{3}\right)$ is also referred to as a strategy profile. The cost function $H_{i}$ of player $i$ is defined on all strategy profiles and will be specified further on. Each player will choose the base stock level that minimizes his cost. 
Special interest goes to equilibria, or stable outcomes, of the game. Let

$$
r_{1}\left(y_{2}, y_{3}\right)=\left\{y_{1} \in Y_{1} \mid H_{1}\left(y_{1}, y_{2}, y_{3}\right) \leq H_{1}\left(y_{1}^{\prime}, y_{2}, y_{3}\right) \text { for all } y_{1}^{\prime} \in Y_{1}\right\}
$$

be the set of best base stock levels for installation 1 given the levels $y_{2}$ and $y_{3}$ of the other installations. The function $r_{1}$ is called a best reply function of installation 1 . The best reply function $r_{2}\left(y_{1}, y_{3}\right)$ of installation 2 and $r_{3}\left(y_{1}, y_{2}\right)$ of installation 3 are defined similarly. Now if a strategy profile $\left(\bar{y}_{1}, \bar{y}_{2}, \bar{y}_{3}\right)$ satisfies

$$
\bar{y}_{1} \in r_{1}\left(\bar{y}_{2}, \bar{y}_{3}\right), \quad \bar{y}_{2} \in r_{2}\left(\bar{y}_{1}, \bar{y}_{3}\right), \quad \bar{y}_{3} \in r_{3}\left(\bar{y}_{1}, \bar{y}_{2}\right)
$$

then it is a Nash equilibrium.

\section{Three-echelon serial systems under decentralized control}

In this Section we assume that the three installations act on their own, that is, we are dealing with a three-echelon serial system under decentralized control. If $y_{i}$ denotes the base stock level of installation $i$ then the real order-up-to level as experienced by installation 3 is also $y_{3}$, because he will never suffer from deficits. If $y_{2}>y_{3}-u_{l_{3}}$ then installation 2 is confronted with a shortage at installation 3 and his new base stock level is $y_{3}-u_{l_{3}}$ instead of $y_{2}$. Therefore he experiences the order-up-to level $w_{2}=\min \left(y_{3}-u_{l_{3}}, y_{2}\right)$ and similarly installation 1 experiences $w_{1}=\min \left(w_{2}-u_{l_{2}}, y_{1}\right)$. These real order-up-to levels are useful in simplifying the expression for the average cost of the system. For this, let $\mathbb{E}$ denote the expectation with regard to the random demand and let $\underline{w}_{i}$ indicate that $w_{i}$ is a function of this random demand.

Lemma 3.1 The average cost of a three-echelon serial system is equal to

$$
D_{3}\left(y_{1}, y_{2}, y_{3}\right)=h_{3}\left(y_{3}-\left(l_{3}+1\right) \mu\right)+\mathbb{E} D_{2}\left(y_{1}, \underline{w}_{2}\right),
$$

where

$$
D_{2}\left(y_{1}, w_{2}\right)=h_{2}\left(w_{2}-\left(l_{2}+1\right) \mu\right)+\mathbb{E} D_{1}\left(\underline{w}_{1}\right)
$$

and

$$
D_{1}\left(w_{1}\right)=h_{1}\left(w_{1}-\left(l_{1}+1\right) \mu\right)+\left(p+h_{1}+h_{2}+h_{3}\right) \int_{w_{1}}^{\infty}\left(u_{l_{1}+1}-w_{1}\right) d F_{l_{1}+1}\left(u_{l_{1}+1}\right) .
$$

The above expression for the average cost $D_{3}\left(y_{1}, y_{2}, y_{3}\right)$ of the system was obtained from the assignment of certain one-period costs to the echelons. These costs are not the real oneperiod costs of the echelons. The true one-period cost for installation 1 consists of holding cost $h_{1}+h_{2}+h_{3}$ if there are goods in stock and penalty cost $p$ otherwise,

$$
\tilde{L}_{1}\left(x_{1}\right)=\left(h_{1}+h_{2}+h_{3}\right) \int_{0}^{x_{1}}\left(x_{1}-u\right) \mathrm{d} F(u)+p \int_{x_{1}}^{\infty}\left(u-x_{1}\right) \mathrm{d} F(u) .
$$

This implies the expected true average cost

$$
\tilde{D}_{1}\left(y_{1}\right)=\int_{0}^{\infty} \tilde{L}_{1}\left(y_{1}-u_{l_{1}}\right) \mathrm{d} F_{l_{1}}\left(u_{l_{1}}\right)=D_{1}\left(y_{1}\right)+\left(h_{2}+h_{3}\right)\left(y_{1}-\left(l_{1}+1\right) \mu\right)
$$


for the one-echelon system with base stock level $y_{1}$. Since the real order-up-to level for installation 1 in a three-echelon system is not $y_{1}$ but $w_{1}$, the expected cost for this installation, $\tilde{H}_{1}\left(y_{1}, y_{2}, y_{3}\right)$, is $\tilde{H}_{1}\left(y_{1}, y_{2}, y_{3}\right)=\mathbb{E} \tilde{D}_{1}\left(\underline{w}_{1}\right)$. The true expected cost $\tilde{H}_{2}$ for installation 2 consists of inventory cost for goods in transit to 1 and inventory cost, if any, for goods that remain after fulfilling the order of echelon 1 ,

$$
\tilde{H}_{2}\left(y_{1}, y_{2}, y_{3}\right)=\left(h_{2}+h_{3}\right) l_{1} \mu+\left(h_{2}+h_{3}\right) \mathbb{E} \int_{0}^{\infty} \max \left(\underline{w}_{2}-u_{l_{2}}-y_{1}, 0\right) \mathrm{d} F_{l_{2}}\left(u_{l_{2}}\right) .
$$

The true cost $\tilde{H}_{3}$ for installation 3 are defined similarly as for 2 . Let $\hat{w}_{i}=\mathbb{E} \underline{w}_{i}$ denote the expected order-up-to level of installation $i$. Rewriting the cost functions results in the following expressions.

Lemma 3.2 The expected true costs for the three installations are equal to

$$
\begin{aligned}
& \tilde{H}_{1}\left(y_{1}, y_{2}, y_{3}\right)=\mathbb{E} D_{1}\left(\underline{w}_{1}\right)+\left(h_{2}+h_{3}\right)\left(\hat{w}_{1}-\left(l_{1}+1\right) \mu\right), \\
& \tilde{H}_{2}\left(y_{1}, y_{2}, y_{3}\right)=\left(h_{2}+h_{3}\right) l_{1} \mu+\left(h_{2}+h_{3}\right)\left(\hat{w}_{2}-l_{2} \mu-\hat{w}_{1}\right),
\end{aligned}
$$

and

$$
\tilde{H}_{3}\left(y_{1}, y_{2}, y_{3}\right)=h_{3} l_{2} \mu+h_{3}\left(y_{3}-l_{3} \mu-\hat{w}_{2}\right) \text {. }
$$

These cost functions distribute the total cost $D_{3}$ of the system among the installations.

Lemma 3.3 $\sum_{i=1}^{3} \tilde{H}_{i}\left(y_{1}, y_{2}, y_{3}\right)=D_{3}\left(y_{1}, y_{2}, y_{3}\right)$

In the strategic game with cost functions $\tilde{H}_{i}$ each installation will choose a base stock level that minimizes its cost. Recall that the base stock levels satisfy $y_{3} \geq y_{2} \geq y_{1}$ since all firms track echelon inventories. Therefore, installation 3 minimizes its cost $\tilde{H}_{3}$ in $y_{3}=y_{2}$. Similarly, installation 2 will set $y_{2}=y_{1}$. Hence, neither of these installations will keep any extra stock. Knowing this, installation 1 will minimize its cost $\tilde{H}_{1}$ in $y_{1}=\tilde{S}_{1}$ where $\tilde{S}_{1}>S_{1}$. Therefore, the Nash equilibrium of the game under decentralized control equals $\left(y_{1}, y_{2}, y_{3}\right)=\left(\tilde{S}_{1}, \tilde{S}_{1}, \tilde{S}_{1}\right)$. This implies that installation 1 is confronted with large costs because it is very likely that there are material shortages at either installation 2 or 3 . Because of this most unfavorable outcome installation 1 would like the installations 2 and 3 to set $y_{j}>y_{1}, j=2,3$, such that the probability of a material shortage decreases and consequently the costs of 1 decrease. But $y_{j}>y_{1}$ increases the inventory cost of installation $j$. Thus installation $j$ is only willing to increase $y_{j}$ to a level above $y_{1}$ if he is compensated for his extra costs. In the next Section we study a proposal initiated by installation 1 for compensation of the installations 2 and 3. This proposal coordinates the serial chain.

\section{Coordination mechanism for serial systems}

In practice it does not seem likely that the installations 1 and 3 communicate directly since installation 2 is in between. Naturally, the installations only talk with their neighbors in the serial system. Figure 1 shows this situation, where the arrows indicate the communication possibilities. Assume that the installations communicate in this way. 
Fig. 1 Serial communication between the three installations

Under decentralized control the installations in a three-echelon serial system will choose base stock levels $\left(y_{1}, y_{2}, y_{3}\right)=\left(\tilde{S}_{1}, \tilde{S}_{1}, \tilde{S}_{1}\right)$, as argued in the previous section. In that situation installation 1 has a large base stock level and is therefore confronted with large costs. To be able to lower his base stock level, and consequently his cost, this installation initiates negotiations with installation 2 with the goal of achieving lower costs by means of coordination of actions.

\subsection{Coordination between the installations 1 and 2}

The following coordination mechanism is proposed. Installation 1 asks installation 2 to keep some stock, that is, to set $y_{2}$ such that $y_{2}>y_{1}$. This increases the cost of installation 2 because now he also has to pay for the inventory cost of his extra stock. Installation 1 offers the following compensation. First, installation 2 is fully compensated for his increase in inventory cost. This implies that installation 2 has no additional cost compared to the situation before negotiation, but also no additional gain. Second, to persuade installation 2 to accept this offer, he also receives a part of the so-called surplus of 1 , which is its cost savings less the compensation paid to installation 2 . This is the gain of installation 2 from this negotiation.

If installation 2 sets $y_{2}>y_{1}$ then his cost increases by $\tilde{H}_{2}\left(y_{1}, y_{2}, y_{3}\right)-\tilde{H}_{2}\left(\tilde{S}_{1}, \tilde{S}_{1}, \tilde{S}_{1}\right)$ whereas the cost of 1 decreases by $\tilde{H}_{1}\left(\tilde{S}_{1}, \tilde{S}_{1}, \tilde{S}_{1}\right)-\tilde{H}_{1}\left(y_{1}, y_{2}, y_{3}\right)$. Installation 1 fully compensates installation 2 for his cost increase. After this, the cost savings of 1 are reduced to

$$
\begin{aligned}
& \tilde{H}_{1}\left(\tilde{S}_{1}, \tilde{S}_{1}, \tilde{S}_{1}\right)-\tilde{H}_{1}\left(y_{1}, y_{2}, y_{3}\right)-\left(\tilde{H}_{2}\left(y_{1}, y_{2}, y_{3}\right)-\tilde{H}_{2}\left(\tilde{S}_{1}, \tilde{S}_{1}, \tilde{S}_{1}\right)\right) \\
& \quad=D_{3}\left(\tilde{S}_{1}, \tilde{S}_{1}, \tilde{S}_{1}\right)-\tilde{H}_{3}\left(\tilde{S}_{1}, \tilde{S}_{1}, \tilde{S}_{1}\right)-\left(D_{3}\left(y_{1}, y_{2}, y_{3}\right)-\tilde{H}_{3}\left(y_{1}, y_{2}, y_{3}\right)\right),
\end{aligned}
$$

where the equality follows from Lemma 3.3. Call this value the surplus of installation 1, or surplus- 1 in short. Installation 1 will give installation 2 a fraction $\alpha, 0<\alpha<1$, of this surplus. Notice that the bounds for $\alpha$ are strict since installation 1 likes to keep a part of his surplus for himself while installation 2 wants to receive something extra next to being compensated for his cost increase.

Let $H_{i}^{\prime}$ denote the cost of installation $i, i=1,2$, after the compensation. Then

$$
\begin{aligned}
& H_{1}^{\prime}\left(y_{1}, y_{2}, y_{3}\right) \\
& =\tilde{H}_{1}\left(y_{1}, y_{2}, y_{3}\right)+\left(\tilde{H}_{2}\left(y_{1}, y_{2}, y_{3}\right)-\tilde{H}_{2}\left(\tilde{S}_{1}, \tilde{S}_{1}, \tilde{S}_{1}\right)\right) \\
& \quad+\alpha\left(D_{3}\left(\tilde{S}_{1}, \tilde{S}_{1}, \tilde{S}_{1}\right)-\tilde{H}_{3}\left(\tilde{S}_{1}, \tilde{S}_{1}, \tilde{S}_{1}\right)-\left(D_{3}\left(y_{1}, y_{2}, y_{3}\right)-\tilde{H}_{3}\left(y_{1}, y_{2}, y_{3}\right)\right)\right) \\
& =(1-\alpha)\left(D_{3}\left(y_{1}, y_{2}, y_{3}\right)-\tilde{H}_{3}\left(y_{1}, y_{2}, y_{3}\right)\right) \\
& \quad+\alpha\left(D_{3}\left(\tilde{S}_{1}, \tilde{S}_{1}, \tilde{S}_{1}\right)-\tilde{H}_{3}\left(\tilde{S}_{1}, \tilde{S}_{1}, \tilde{S}_{1}\right)\right)-\tilde{H}_{2}\left(\tilde{S}_{1}, \tilde{S}_{1}, \tilde{S}_{1}\right)
\end{aligned}
$$

and

$$
\begin{aligned}
& H_{2}^{\prime}\left(y_{1}, y_{2}, y_{3}\right) \\
& \quad=\tilde{H}_{2}\left(y_{1}, y_{2}, y_{3}\right)-\left(\tilde{H}_{2}\left(y_{1}, y_{2}, y_{3}\right)-\tilde{H}_{2}\left(\tilde{S}_{1}, \tilde{S}_{1}, \tilde{S}_{1}\right)\right)
\end{aligned}
$$




$$
\begin{aligned}
& -\alpha\left(D_{3}\left(\tilde{S}_{1}, \tilde{S}_{1}, \tilde{S}_{1}\right)-\tilde{H}_{3}\left(\tilde{S}_{1}, \tilde{S}_{1}, \tilde{S}_{1}\right)-\left(D_{3}\left(y_{1}, y_{2}, y_{3}\right)-\tilde{H}_{3}\left(y_{1}, y_{2}, y_{3}\right)\right)\right) \\
= & \alpha\left(D_{3}\left(y_{1}, y_{2}, y_{3}\right)-\tilde{H}_{3}\left(y_{1}, y_{2}, y_{3}\right)\right) \\
& -\alpha\left(D_{3}\left(\tilde{S}_{1}, \tilde{S}_{1}, \tilde{S}_{1}\right)-\tilde{H}_{3}\left(\tilde{S}_{1}, \tilde{S}_{1}, \tilde{S}_{1}\right)\right)+\tilde{H}_{2}\left(\tilde{S}_{1}, \tilde{S}_{1}, \tilde{S}_{1}\right) .
\end{aligned}
$$

Notice that the new cost functions are a rearrangement of the former ones,

$$
H_{1}^{\prime}\left(y_{1}, y_{2}, y_{3}\right)+H_{2}^{\prime}\left(y_{1}, y_{2}, y_{3}\right)=\tilde{H}_{1}\left(y_{1}, y_{2}, y_{3}\right)+\tilde{H}_{2}\left(y_{1}, y_{2}, y_{3}\right) .
$$

During these negotiations the base stock level of installation 3 remains unchanged, namely $y_{3}=y_{2}$. This equality says that installation 3 keeps no stock and only has to pay the inventory cost of goods in transit to installation 2 . This cost $\tilde{H}_{3}\left(y_{1}, y_{2}, y_{2}\right)=h_{3} l_{2} \mu$ is independent from $y_{1}$ and $y_{2}$. Therefore, minimizing both $H_{1}^{\prime}$ and $H_{2}^{\prime}$ under $y_{3}=y_{2}$ is equivalent to minimizing $D_{3}\left(y_{1}, y_{2}, y_{2}\right)$. This minimization has a remarkable outcome.

Theorem 4.1 The cost function $D_{3}\left(y_{1}, y_{2}, y_{2}\right)$ is minimized in $y_{1}=S_{1}$, the optimal base stock level of installation 1 under centralized control, and $y_{2}=\tilde{S}_{2}>S_{2}$.

Hence, installation 1 minimizes his new cost function by setting his base stock level equal to his optimal level under centralized control. Installation 2 picks a base stock level larger than his optimal level under centralized control. Both parties will agree on this outcome only if it results in decreased individual costs.

Theorem 4.2 In the minimum $\left(y_{1}, y_{2}, y_{3}\right)=\left(S_{1}, \tilde{S}_{2}, \tilde{S}_{2}\right)$, surplus-1 equals $D_{3}\left(\tilde{S}_{1}, \tilde{S}_{1}, \tilde{S}_{1}\right)-$ $D_{3}\left(S_{1}, \tilde{S}_{2}, \tilde{S}_{2}\right)>0$. The installations 1 and 2 are better off under coordination because $H_{i}^{\prime}\left(S_{1}, \tilde{S}_{2}, \tilde{S}_{2}\right)<\tilde{H}_{i}\left(\tilde{S}_{1}, \tilde{S}_{1}, \tilde{S}_{1}\right), i=1,2$.

Thus, the coordination results in lower costs for the installations 1 and 2 . Both are better off and agree to use this coordination mechanism.

\subsection{Coordination between the installations 2 and 3}

The negotiation between the installations 1 and 2 ends in the base stock levels $\left(S_{1}, \tilde{S}_{2}, \tilde{S}_{2}\right)$. The levels of the installations 2 and 3 are equal, because 3 still does not keep stock and consequently, 2 is confronted with large costs. He would like installation 3 to keep some stock, that is $y_{3}>y_{2}$, so as to decrease his own costs. In exchange, installation 2 offers him a compensation for his increase in cost plus a part of the so-called surplus-2. All along, the base stock level of installation 1 remains $S_{1}$, the result of the previous coordination.

Although installation 2 negotiates with installation 3, the negotiations do not only affect installation 2 but also installation 1. Any resulting cost savings for installation 2 result in lower compensations to be paid by installation 1. In other words, the negotiations lead to cost savings for echelon 2. Knowing this, installation 1 will have no problems with installation 2 negotiating with installation 3 on behalf of echelon 2 . And that is exactly what will happen.

One part of the compensation is surplus-2, which is the remainder of the cost savings of echelon 2 after compensating installation 3 for his increased costs:

$$
\begin{aligned}
\text { Surplus-2 }= & H_{1}^{\prime}\left(S_{1}, \tilde{S}_{2}, \tilde{S}_{2}\right)+H_{2}^{\prime}\left(S_{1}, \tilde{S}_{2}, \tilde{S}_{2}\right)-\left(H_{1}^{\prime}\left(S_{1}, y_{2}, y_{3}\right)+H_{2}^{\prime}\left(S_{1}, y_{2}, y_{3}\right)\right) \\
& -\left(\tilde{H}_{3}\left(S_{1}, y_{2}, y_{3}\right)-\tilde{H}_{3}\left(S_{1}, \tilde{S}_{2}, \tilde{S}_{2}\right)\right) \\
= & D_{3}\left(S_{1}, \tilde{S}_{2}, \tilde{S}_{2}\right)-D_{3}\left(S_{1}, y_{2}, y_{3}\right) .
\end{aligned}
$$


Installation 3 receives a fraction $\beta, 0<\beta<1$, of this surplus. This should persuade him to accept the deal with installation 2 because it results in costs that are lower than before the negotiation.

Let $H_{i}$ denote the cost of installation $i$ after the compensation. Then

$$
\begin{aligned}
( & \left.H_{1}+H_{2}\right)\left(S_{1}, y_{2}, y_{3}\right) \\
= & H_{1}^{\prime}\left(S_{1}, y_{2}, y_{3}\right)+H_{2}^{\prime}\left(S_{1}, y_{2}, y_{3}\right)+\left(\tilde{H}_{3}\left(S_{1}, y_{2}, y_{3}\right)-\tilde{H}_{3}\left(S_{1}, \tilde{S}_{2}, \tilde{S}_{2}\right)\right) \\
& \quad+\beta\left(D_{3}\left(S_{1}, \tilde{S}_{2}, \tilde{S}_{2}\right)-D_{3}\left(S_{1}, y_{2}, y_{3}\right)\right) \\
= & (1-\beta) D_{3}\left(S_{1}, y_{2}, y_{3}\right)-\tilde{H}_{3}\left(S_{1}, \tilde{S}_{2}, \tilde{S}_{2}\right)+\beta D_{3}\left(S_{1}, \tilde{S}_{2}, \tilde{S}_{2}\right)
\end{aligned}
$$

and

$$
\begin{aligned}
H_{3} & \left(S_{1}, y_{2}, y_{3}\right) \\
= & \tilde{H}_{3}\left(S_{1}, y_{2}, y_{3}\right)-\left(\tilde{H}_{3}\left(S_{1}, y_{2}, y_{3}\right)-\tilde{H}_{3}\left(S_{1}, \tilde{S}_{2}, \tilde{S}_{2}\right)\right) \\
& \quad-\beta\left(D_{3}\left(S_{1}, \tilde{S}_{2}, \tilde{S}_{2}\right)-D_{3}\left(S_{1}, y_{2}, y_{3}\right)\right) \\
= & \beta D_{3}\left(S_{1}, y_{2}, y_{3}\right)+\tilde{H}_{3}\left(S_{1}, \tilde{S}_{2}, \tilde{S}_{2}\right)-\beta D_{3}\left(S_{1}, \tilde{S}_{2}, \tilde{S}_{2}\right) .
\end{aligned}
$$

One sees from these expressions that minimizing both cost functions boils down to minimizing $D_{3}\left(S_{1}, y_{2}, y_{3}\right)$.

Theorem 4.3 The cost function $D_{3}\left(S_{1}, y_{2}, y_{3}\right)$ is minimized in $y_{2}=S_{2}$ and $y_{3}=S_{3}$. Therefore, the base stock levels become $\left(S_{1}, y_{2}, y_{3}\right)=\left(S_{1}, S_{2}, S_{3}\right)$, the global optimum. In this minimum, surplus-2 equals $D_{3}\left(S_{1}, \tilde{S}_{2}, \tilde{S}_{2}\right)-D_{3}\left(S_{1}, S_{2}, S_{3}\right)>0$. The installations 1 and 2 and installation 3 are better off than before coordination because $\left(H_{1}+H_{2}\right)\left(S_{1}, S_{2}, S_{3}\right)<$ $\left(H_{1}^{\prime}+H_{2}^{\prime}\right)\left(S_{1}, \tilde{S}_{2}, \tilde{S}_{2}\right)$ and $H_{3}\left(S_{1}, S_{2}, S_{3}\right)<\tilde{H}_{3}\left(S_{1}, \tilde{S}_{2}, \tilde{S}_{2}\right)$.

The coordination mechanism proposed in the negotiations result in each installation choosing its optimal base stock level as under centralized control. Hence, this mechanism ensures that the optimal individual decisions of the selfish installations are also optimal for the entire serial system.

The cost $\left(H_{1}+H_{2}\right)\left(S_{1}, S_{2}, S_{3}\right)$ of echelon 2 has to be divided among the installations 1 and 2. Recall that this cost consists of the individual costs $H_{i}^{\prime}\left(S_{1}, S_{2}, S_{3}\right)$ of installation $i=1,2$ and the compensation paid to installation $3,\left(\tilde{H}_{3}\left(S_{1}, S_{2}, S_{3}\right)-\tilde{H}_{3}\left(S_{1}, \tilde{S}_{2}, \tilde{S}_{2}\right)\right)+$ $\beta\left(D_{3}\left(S_{1}, \tilde{S}_{2}, \tilde{S}_{2}\right)-D_{3}\left(S_{1}, S_{2}, S_{3}\right)\right)$. Naturally, each installation pays its own individual cost. Further, since installation 2 negotiates directly with installation 3 due to serial communication, he should pay the compensation to 3. This cost division may seem unfavorable for installation 2 and resulting in large costs because he has to pay something extra besides his own cost, but that need not be true. The change in base stock levels from $\left(S_{1}, \tilde{S}_{2}, \tilde{S}_{2}\right)$ to $\left(S_{1}, S_{2}, S_{3}\right)$ results in an increase of surplus-1 of $\left(H_{1}^{\prime}+H_{2}^{\prime}\right)\left(S_{1}, \tilde{S}_{2}, \tilde{S}_{2}\right)-$ $\left(H_{1}^{\prime}+H_{2}^{\prime}\right)\left(S_{1}, S_{2}, S_{3}\right)$. Due to this increase, installation 2 receives an extra amount of $\alpha\left(\left(H_{1}^{\prime}+H_{2}^{\prime}\right)\left(S_{1}, \tilde{S}_{2}, \tilde{S}_{2}\right)-\left(H_{1}^{\prime}+H_{2}^{\prime}\right)\left(S_{1}, S_{2}, S_{3}\right)\right)$ from installation 1 . This covers the compensation installation 2 has to pay to installation 3 if $\alpha$ satisfies

$$
\alpha>\frac{\tilde{H}_{3}\left(S_{1}, S_{2}, S_{3}\right)-\tilde{H}_{3}\left(S_{1}, \tilde{S}_{2}, \tilde{S}_{2}\right)+\beta\left(D_{3}\left(S_{1}, \tilde{S}_{2}, \tilde{S}_{2}\right)-D_{3}\left(S_{1}, S_{2}, S_{3}\right)\right)}{\left(H_{1}^{\prime}+H_{2}^{\prime}\right)\left(S_{1}, \tilde{S}_{2}, \tilde{S}_{2}\right)-\left(H_{1}^{\prime}+H_{2}^{\prime}\right)\left(S_{1}, S_{2}, S_{3}\right)}=: \underline{\alpha} .
$$

The fraction $\alpha$ should be larger than some lower bound $\underline{\alpha}$, the compensation paid to installation 3 divided by the increase of surplus-1. Notice that $\underline{\alpha}<1$. 
Lemma 4.4 The cost division results in a cost reduction for installation $1, H_{1}^{\prime}\left(S_{1}, S_{2}, S_{3}\right)<$ $H_{1}^{\prime}\left(S_{1}, \tilde{S}_{2}, \tilde{S}_{2}\right)$. Installation 2 saves cost, $H_{2}^{\prime}\left(S_{1}, S_{2}, S_{3}\right)+$ compensation to $3<H_{2}^{\prime}\left(S_{1}\right.$, $\left.\tilde{S}_{2}, \tilde{S}_{2}\right)$, if $\alpha>\underline{\alpha}$.

We conclude that both installations save cost if $\alpha$ is large enough. The overall result of the negotiations is summarized in the Theorem below.

Theorem 4.5 Consider the strategic game played by the installations, where the cost functions of the installations 1,2 and 3 are $H_{1}^{\prime}, H_{2}^{\prime}$ and $H_{3}$ due to the coordination mechanism. If installation 2 pays the compensation to installation 3 and if $\alpha>\underline{\alpha}$ then the strategy profile $\left(y_{1}, y_{2}, y_{3}\right)=\left(S_{1}, S_{2}, S_{3}\right)$ is the unique Nash equilibrium in this game.

This result shows that under the right incentives the selfish installations take decisions that are also optimal for the entire serial system. Besides all installations accept the incentives because it results in cost savings for each of them.

\subsection{Implementation in practice}

In this subsection we show how the coordination mechanism can be implemented in practice in a three-echelon serial system. (This practical implementation is not related to the gametheoretic notion of implementation theory as in Osborne and Rubinstein (1994).)

Installation 1 starts its coordination with installation 2 by asking him to set $y_{2}>y_{1}$ instead of $y_{2}=y_{1}$ under individual optimization. Suppose installation 2 does so. He announces the use of base stock level $y_{2}$ whereas installation 1 announces the use of $y_{1}$. Let $v_{t_{1}, t_{2}}$ denote the realized cumulative demand over the periods $t_{1}, t_{1}+1, \ldots, t_{2}-1, t_{2}$.

At the beginning of period $t+l_{3}$ installation 2 places an order to bring his echelon inventory position to $y_{2}$. Due to a possible shortage at his supplier, installation 3, his actual echelon inventory position is $\min \left(y_{3}-v_{t, t+l_{3}-1}, y_{2}\right)$. At the beginning of period $t+l_{3}+l_{2}$ his echelon stock becomes $\min \left(y_{3}-v_{t, t+l_{3}-1}, y_{2}\right)-v_{t+l_{3}, t+l_{3}+l_{2}-1}$. Now installation 1 wants to raise his echelon inventory position to $y_{1}$. This request by installation 1 can only be fulfilled by installation 2 if the amount requested is smaller than his stock, that is, $y_{1} \leq$ $\min \left(y_{3}-v_{t, t+l_{3}-1}, y_{2}\right)-v_{t+l_{3}, t+l_{3}+l_{2}-1}$.

These changes in inventory position influence the costs of both players as follows. First, due to his larger base stock level $y_{2}$ installation 2 may be faced with unsold goods for which he has to pay additional inventory costs at the end of period $t+l_{3}+l_{2}+l_{1}$, namely

$$
\left(h_{2}+h_{3}\right) \max \left(\min \left(y_{3}-v_{t, t+l_{3}-1}, y_{2}\right)-v_{t+l_{3}, t+l_{3}+l_{2}-1}-y_{1}, 0\right) .
$$

This extra cost will be refunded by installation 1 . Its expected value is $\tilde{H}_{2}\left(y_{1}, y_{2}, y_{3}\right)-$ $\tilde{H}_{2}\left(\tilde{S}_{1}, \tilde{S}_{1}, \tilde{S}_{1}\right)$ and leads to the modified costs $\tilde{H}_{1}\left(y_{1}, y_{2}, y_{3}\right)+\left(\tilde{H}_{2}\left(y_{1}, y_{2}, y_{3}\right)-\right.$ $\left.\tilde{H}_{2}\left(\tilde{S}_{1}, \tilde{S}_{1}, \tilde{S}_{1}\right)\right)$ for installation 1 and $\tilde{H}_{2}\left(\tilde{S}_{1}, \tilde{S}_{1}, \tilde{S}_{1}\right)$ for installation 2 . Notice that installation 2 is indifferent between being refunded and staying in the initial situation.

The second part of the compensation paid by installation 1 to installation 2 is a fraction of the actual surplus of installation 1. This actual surplus is the difference between the actual cost savings of installation 1 and the cost increase compensated to installation 2. Initially, installation 1 uses base stock level $y_{1}=\tilde{S}_{1}$. He can calculate this level because it minimizes his cost function, $\tilde{S}_{1}=\arg \min _{y_{1}} \tilde{H}_{1}\left(y_{1}, y_{1}, y_{1}\right)$. At the end of period $t+l_{3}+l_{2}+l_{1}$ the actual inventory position of installation 1 is

$$
I P_{1}=\min \left(\min \left(y_{3}-v_{t, t+l_{3}-1}, y_{2}\right)-v_{t+l_{3}, t+l_{3}+l_{2}-1}, y_{1}\right)-v_{t+l_{3}+l_{2}, t+l_{3}+l_{2}+l_{1}}
$$


while it would have been $\tilde{S}_{1}-v_{t, t+l_{3}+l_{2}+l_{1}}$ in the initial situation. Both these inventory positions can be measured by keeping track of demand in the past $l_{3}+l_{2}+l_{1}+1$ periods. The actual inventory cost of installation 1 at the end of period $t+l_{3}+l_{2}+l_{1}$ is

$$
\left(h_{1}+h_{2}+h_{3}\right) \max \left(I P_{1}, 0\right)+p \max \left(-I P_{1}, 0\right)
$$

while they are

$$
\left(h_{1}+h_{2}+h_{3}\right) \max \left(\tilde{S}_{1}-v_{t, t+l_{3}+l_{2}+l_{1}+1}, 0\right)+p \max \left(v_{t, t+l_{3}+l_{2}+l_{1}+1}-\tilde{S}_{1}, 0\right)
$$

in the initial situation.

The transfer paid by installation 1 to installation 2 in this period is a fraction $\alpha$ of the actual cost savings of installation 1 minus the compensation for installation 2

$$
\begin{aligned}
& \left(h_{1}+h_{2}+h_{3}\right) \max \left(\tilde{S}_{1}-v_{t, t+l_{3}+l_{2}+l_{1}+1}, 0\right)+p \max \left(v_{t, t+l_{3}+l_{2}+l_{1}+1}-\tilde{S}_{1}, 0\right) \\
& -\left(\left(h_{1}+h_{2}+h_{3}\right) \max \left(I P_{1}, 0\right)+p \max \left(-I P_{1}, 0\right)\right) \\
& -\left(h_{2}+h_{3}\right) \max \left(\min \left(y_{3}-v_{t, t+l_{3}-1}, y_{2}\right)-v_{t+l_{3}, t+l_{3}+l_{2}-1}-y_{1}, 0\right) .
\end{aligned}
$$

Installation 3's policy remains $y_{3}=y_{2}$ and therefore the expected transfer $T\left(y_{1}, y_{2}, y_{2}\right)$ is

$$
\begin{aligned}
T\left(y_{1}, y_{2}, y_{2}\right) & =\alpha\left[\tilde{H}_{1}\left(\tilde{S}_{1}, \tilde{S}_{1}, \tilde{S}_{1}\right)-\tilde{H}_{1}\left(y_{1}, y_{2}, y_{2}\right)-\left(\tilde{H}_{2}\left(y_{1}, y_{2}, y_{2}\right)-\tilde{H}_{2}\left(\tilde{S}_{1}, \tilde{S}_{1}, \tilde{S}_{1}\right)\right)\right] \\
& =\alpha\left[D_{3}\left(\tilde{S}_{1}, \tilde{S}_{1}, \tilde{S}_{1}\right)-D_{3}\left(y_{1}, y_{2}, y_{2}\right)\right]
\end{aligned}
$$

where the last equality follows from Lemma 3.3 and $\tilde{H}_{3}\left(y_{1}, y_{2}, y_{2}\right)=\tilde{H}_{3}\left(\tilde{S}_{1}, \tilde{S}_{1}, \tilde{S}_{1}\right)=$ $h_{3} l_{2} \mu$. The payment changes the cost of installation 1 to

$$
\tilde{H}_{1}\left(y_{1}, y_{2}, y_{3}\right)+\left(\tilde{H}_{2}\left(y_{1}, y_{2}, y_{3}\right)-\tilde{H}_{2}\left(\tilde{S}_{1}, \tilde{S}_{1}, \tilde{S}_{1}\right)\right)+T\left(y_{1}, y_{2}, y_{2}\right)=H_{1}^{\prime}\left(y_{1}, y_{2}, y_{2}\right)
$$

and the cost of installation 2 to

$$
\tilde{H}_{2}\left(\tilde{S}_{1}, \tilde{S}_{1}, \tilde{S}_{1}\right)-T\left(y_{1}, y_{2}, y_{2}\right)=H_{2}^{\prime}\left(y_{1}, y_{2}, y_{2}\right) \text {. }
$$

Hence, the optimal choice of base stock levels is $\left(y_{1}, y_{2}, y_{2}\right)=\left(S_{1}, \tilde{S}_{2}, \tilde{S}_{2}\right)$ (see Theorem 4.1) resulting in costs $H_{i}^{\prime}\left(S_{1}, \tilde{S}_{2}, \tilde{S}_{2}\right)$ for installation $i$. Therefore, the coordination between the installations 1 and 2 can be implemented in practice by considering actual costs and keeping track of demands in the past $l_{3}+l_{2}+l_{1}+1$ periods.

Among similar lines the coordination between the installations 2 and 3, as described in Sect. 4.2, can be implemented.

\section{Three-echelon distribution systems under decentralized control}

A three-echelon distribution system consists of one supplier delivering goods to two local retailers. These retailers are denoted by the index $n, n=1,2$, and the supplier by index 3 . The leadtime for delivery of goods to the supplier is $l_{2}$ while the leadtime for all retailers is $l_{1}$. The distribution function of the random demand $u^{(n)}$ at retailer $n$ is denoted by $F^{(n)}$. The cumulative demand per period is denoted by $u$ and its expectation is $\mu$. 
The true one-period cost for retailer $n$ consists of holding and penalty costs. If $x_{n}$ is the echelon stock of retailer $n$ at the beginning of a period then the true cost at the end of that period are

$$
\tilde{L}_{n}\left(x_{n}\right)=\left(h_{1}+h_{2}\right) \int_{0}^{x_{n}}\left(x_{n}-u^{(n)}\right) \mathrm{d} F^{(n)}\left(u^{(n)}\right)+p \int_{x_{n}}^{\infty}\left(u^{(n)}-x_{n}\right) \mathrm{d} F^{(n)}\left(u^{(n)}\right) .
$$

Using $C_{n}\left(y_{n}\right)=\mathbb{E} \tilde{L}_{n}\left(y_{n}-u_{l_{1}}^{(n)}\right)-h_{2}\left(y_{n}-\left(l_{1}+1\right) \mu^{(n)}\right)$ as in Langenhoff and Zijm (1990), the expected average cost for retailer $n$ can be written as

$$
\tilde{D}_{n}\left(y_{n}\right)=\int_{0}^{\infty} \tilde{L}_{n}\left(y_{n}-u_{l_{1}}^{(n)}\right) \mathrm{d} F_{l_{1}}^{(n)}\left(u_{l_{1}}^{(n)}\right)=C_{n}\left(y_{n}\right)+h_{2}\left(y_{n}-\left(l_{1}+1\right) \mu^{(n)}\right)
$$

(compare this to (1)).

The retailers place their orders for replenishment of stock at the supplier. Under the balance assumption in Langenhoff and Zijm (1990), the supplier can distribute his echelon stock $y_{3}-u_{l_{2}}$ among the retailers such that both retailers have an equal probability of stockout, a so-called equal fractile position by Eppen and Schrage (1981). Denote by $z_{n}\left[y_{3}-u_{l_{2}}\right]$ the amount allocated to retailer $n$ according to this distribution.

The real order-up-to level $w_{n}$ for retailer $n$ depends on the base stock levels $y_{n}, n=1,2$, and the echelon stock $y_{3}-u_{l_{2}}$ of the supplier. If the supplier's stock is large enough then the requests of the retailers will be fulfilled. Otherwise, we assume that the supplier distributes his stock among the retailers according to the allocation functions $z_{n}$. Thus,

$$
w_{n}= \begin{cases}y_{n}, & y_{1}+y_{2} \leq y_{3}-u_{l_{2}}, \\ z_{n}\left[y_{3}-u_{l_{2}}\right], & y_{1}+y_{2}>y_{3}-u_{l_{2}}\end{cases}
$$

and $w_{1}+w_{2}=\min \left(y_{1}+y_{2}, y_{3}-u_{l_{2}}\right)$. Notice that in (3) the allocation function $z_{n}$ is used if the supplier has a shortage, $y_{3}-u_{l_{2}}<y_{1}+y_{2}$. In the next section, where a coordination mechanism for distribution systems is discussed, the allocation function $z_{n}$ is also used if the supplier has no shortage, $y_{3}-u_{l_{2}} \geq y_{1}+y_{2}$, to determine the compensation of each retailer to the supplier.

The expected true average cost $\tilde{H}_{n}$ per period for retailer $n$ is $\tilde{H}_{n}\left(y_{1}, y_{2}, y_{3}\right)=\mathbb{E} \tilde{D}_{n}\left(w_{n}\right)$. The expected cost $\tilde{H}_{3}$ per period for the supplier consist of the inventory cost of goods in transit to the retailers and on stock:

$$
\tilde{H}_{3}\left(y_{1}, y_{2}, y_{3}\right)=h_{2} l_{1} \mu+h_{2} \int_{0}^{\infty} \max \left(y_{3}-u_{l_{2}}-\left(y_{1}+y_{2}\right), 0\right) \mathrm{d} F_{l_{2}}\left(u_{l_{2}}\right) .
$$

The cost functions $\tilde{H}_{i}$ divide the total cost $D^{(3)}\left(y_{1}, y_{2}, y_{3}\right)$ of the distribution system among the installations, $\sum_{i=1}^{3} \tilde{H}_{i}\left(y_{1}, y_{2}, y_{3}\right)=D^{(3)}\left(y_{1}, y_{2}, y_{3}\right)$. This total cost $D^{(3)}\left(y_{1}, y_{2}, y_{3}\right)$ is minimized in the optimum under centralized control (the so-called global optimum) $\left(y_{1}, y_{2}, y_{3}\right)=\left(S_{1}, S_{2}, S_{3}\right)$, as shown in Langenhoff and Zijm (1990). For retailer $n$ the value $S_{n}$ also minimizes $C_{n}\left(y_{n}\right)$.

Under decentralized control the supplier will keep its echelon base stock level $y_{3}$ as low as possible, namely $y_{3}=y_{1}+y_{2}$. This way, its costs are only $\tilde{H}_{3}\left(y_{1}, y_{2}, y_{1}+y_{2}\right)=h_{2} l_{1} \mu$. This low base stock level implies $w_{n}=z_{n}\left[y_{1}+y_{2}-u_{l_{2}}\right]<y_{n}$; the retailers always receive less than they ordered. Their costs are

$$
\tilde{H}_{n}\left(y_{1}, y_{2}, y_{1}+y_{2}\right)=\mathbb{E} C_{n}\left(z_{n}\left[y_{1}+y_{2}-u_{l_{2}}\right]\right)+h_{2}\left(\mathbb{E} z_{n}\left[y_{1}+y_{2}-u_{l_{2}}\right]-\left(l_{1}+1\right) \mu^{(n)}\right) .
$$


Minimizing this cost results in $y_{n}=\tilde{S}_{n} \neq S_{n}$. The outcome of the game under decentralized control is $\left(y_{1}, y_{2}, y_{3}\right)=\left(\tilde{S}_{1}, \tilde{S}_{2}, \tilde{S}_{1}+\tilde{S}_{2}\right)$, which is unequal to the global optimum.

\section{Coordination mechanism for distribution systems}

Both retailers are not happy with the outcome under decentralized control, in which the supplier keeps a minimal base stock level $y_{3}=y_{1}+y_{2}$. The following coordination mechanism is proposed. Both retailers ask the supplier to increase his base stock level such that $y_{3}>y_{1}+y_{2}$. This implies a cost increase for the supplier of size

$$
\tilde{H}_{3}\left(y_{1}, y_{2}, y_{3}\right)-\tilde{H}_{3}\left(\tilde{S}_{1}, \tilde{S}_{2}, \tilde{S}_{1}+\tilde{S}_{2}\right)=h_{2} \int_{0}^{\infty}\left(y_{3}-u_{l_{2}}-\left(w_{1}+w_{2}\right)\right) \mathrm{d} F_{l_{2}}\left(u_{l_{2}}\right) .
$$

This extra cost will be compensated by the retailers. Retailer $n$ will pay the part

$$
h_{2} \int_{0}^{\infty}\left(z_{n}\left[y_{3}-u_{l_{2}}\right]-w_{n}\right) \mathrm{d} F_{l_{2}}\left(u_{l_{2}}\right)=h_{2} \mathbb{E}\left(z_{n}\left[y_{3}-u_{l_{2}}\right]-w_{n}\right) \text {. }
$$

This is the expected holding cost of the extra amount received by retailer $n$ if the supplier would always distribute the quantity $y_{3}-u_{l_{2}}$ according to the allocation function $z_{n}$ instead of supplying $w_{n}$. Due to this compensation the supplier is indifferent between cooperating with the retailers and working on his own because both result in equal costs.

The surplus of retailer $n$, his cost savings minus the compensation to the supplier, equals

$$
\tilde{H}_{n}\left(\tilde{S}_{1}, \tilde{S}_{2}, \tilde{S}_{1}+\tilde{S}_{2}\right)-\tilde{H}_{n}\left(y_{1}, y_{2}, y_{3}\right)-h_{2} \mathbb{E}\left(z_{n}\left[y_{3}-u_{l_{2}}\right]-w_{n}\right) .
$$

To provide the supplier with an incentive to cooperate with the retailers, he receives a fraction $\gamma, 0<\gamma<1$, of the surplus of the retailers. Retailer $n$ now faces his own cost, the compensation to the supplier for the cost increase and the payment of a fraction $\gamma$ of his surplus,

$$
\begin{aligned}
& H_{n}\left(y_{1}, y_{2}, y_{3}\right) \\
& =\tilde{H}_{n}\left(y_{1}, y_{2}, y_{3}\right)+h_{2} \mathbb{E}\left(z_{n}\left[y_{3}-u_{l_{2}}\right]-w_{n}\right) \\
& +\gamma\left(\tilde{H}_{n}\left(\tilde{S}_{1}, \tilde{S}_{2}, \tilde{S}_{1}+\tilde{S}_{2}\right)-\tilde{H}_{n}\left(y_{1}, y_{2}, y_{3}\right)-h_{2} \mathbb{E}\left(z_{n}\left[y_{3}-u_{l_{2}}\right]-w_{n}\right)\right) \\
& =(1-\gamma)\left(\tilde{H}_{n}\left(y_{1}, y_{2}, y_{3}\right)+h_{2} \mathbb{E}\left(z_{n}\left[y_{3}-u_{l_{2}}\right]-w_{n}\right)\right)+\gamma \tilde{H}_{n}\left(\tilde{S}_{1}, \tilde{S}_{2}, \tilde{S}_{1}+\tilde{S}_{2}\right) \text {. }
\end{aligned}
$$

These costs are minimized if the retailer sets his base stock level equal to his optimal level under centralized control.

Lemma 6.1 Retailer $n$ minimizes his cost $H_{n}\left(y_{1}, y_{2}, y_{3}\right)$ in $y_{n}=S_{n}$.

The cost of the supplier after being compensated by the retailers is

$$
\begin{aligned}
& H_{3}\left(y_{1}, y_{2}, y_{3}\right) \\
& \quad=\tilde{H}_{3}\left(y_{1}, y_{2}, y_{3}\right)-\sum_{n=1}^{2} h_{2} \mathbb{E}\left(z_{n}\left[y_{3}-u_{l_{2}}\right]-w_{n}\right)
\end{aligned}
$$




$$
\begin{aligned}
& -\sum_{n=1}^{2} \gamma\left(\tilde{H}_{n}\left(\tilde{S}_{1}, \tilde{S}_{2}, \tilde{S}_{1}+\tilde{S}_{2}\right)-\tilde{H}_{n}\left(y_{1}, y_{2}, y_{3}\right)-h_{2} \mathbb{E}\left(z_{n}\left[y_{3}-u_{l_{2}}\right]-w_{n}\right)\right) \\
= & \gamma D^{(3)}\left(y_{1}, y_{2}, y_{3}\right)+\tilde{H}_{3}\left(\tilde{S}_{1}, \tilde{S}_{2}, \tilde{S}_{1}+\tilde{S}_{2}\right)-\gamma D^{(3)}\left(\tilde{S}_{1}, \tilde{S}_{2}, \tilde{S}_{1}+\tilde{S}_{2}\right) .
\end{aligned}
$$

Obviously, if the retailers set $y_{n}=S_{n}$ then $y_{3}=S_{3}$ minimizes the cost of the supplier. This immediately implies the following result, which is presented without proof.

Theorem 6.2 Consider the strategic game played by the supplier and the retailers, where firm $i, i=1,2,3$, has cost function $H_{i}$ due to the coordination mechanism. The strategy profile $\left(y_{1}, y_{2}, y_{3}\right)=\left(S_{1}, S_{2}, S_{3}\right)$ is the unique Nash equilibrium in this game.

The coordination mechanism results in each firm choosing its global optimal base stock level. The incentive to use this mechanism is also present, as shown in the Theorem hereafter.

Theorem 6.3 All firms have a lower cost in the Nash equilibrium than in the initial situation, $H_{i}\left(S_{1}, S_{2}, S_{3}\right)<\tilde{H}_{i}\left(\tilde{S}_{1}, \tilde{S}_{2}, \tilde{S}_{1}+\tilde{S}_{2}\right), i=1,2,3$.

Therefore, also for distribution systems there exists a coordination mechanism that aligns the incentives of the installations with those of the supply chain. Further, each installation accepts the use of the coordination mechanism since it results in cost savings.

\subsection{Implementation in practice}

The practical implementation of the coordination mechanism for a three-echelon distribution system with a supplier and two retailer goes along the same lines as the one for serial systems in Sect. 4.3, but there are some differences. These differences are indicated below.

Let $v_{t_{1}, t_{2}}^{(n)}$ denote the realized cumulative demand over the periods $t_{1}, \ldots, t_{2}$ at retailer $n$ and let $v_{t_{1}, t_{2}}$ be the total demand at both retailers. The retailers 1 and 2 start their coordination with the supplier by asking him to set $y_{3}>y_{1}+y_{2}$ instead of $y_{3}=y_{1}+y_{2}$ under individual optimization. Suppose that at the beginning of period $t$ the supplier decides to return his echelon inventory position to $y_{3}$ and at the beginning of period $t+l_{2}$ retailer $n, n=1,2$, wants to raise his echelon inventory position to $y_{n}$. Due to the increased base stock level $y_{3}$ the supplier may be faced with unsold goods for which he has to pay (additional) inventory costs at the end of period $t+l_{2}+l_{1}$, namely $h_{2} \max \left(y_{3}-v_{t, t+l_{2}-1}-\left(y_{1}+y_{2}\right), 0\right)$. This extra cost will be refunded by the retailers: $h_{2} \max \left(z_{n}\left[y_{3}-v_{t, t+l_{2}-1}\right]-y_{n}, 0\right)$ is paid by retailer $n$.

The second part of the compensation paid by the retailers to the supplier is a fraction $\gamma$ of the actual surplus of the retailers. This actual surplus is the difference between the actual cost savings of the retailer and the cost refunded to the supplier:

$$
\begin{aligned}
& \left(h_{1}+h_{2}\right) \max \left(\tilde{S}_{n}-v_{t, t+l_{2}+l_{1}}^{(n)}, 0\right)+p \max \left(v_{t, t+l_{2}+l_{1}}^{(n)}-\tilde{S}_{n}, 0\right) \\
& -\left(\left(h_{1}+h_{2}\right) \max \left(I P_{n}, 0\right)+p \max \left(-I P_{n}, 0\right)\right) \\
& -h_{2} \max \left(z_{n}\left[y_{3}-v_{t, t+l_{2}-1}\right]-y_{n}, 0\right),
\end{aligned}
$$

where

$$
I P_{n}= \begin{cases}y_{n}-v_{t+l_{2}, t+l_{2}+l_{1}}^{(n)}, & y_{3}-v_{t, t+l_{2}-1} \geq y_{1}+y_{2}, \\ z_{n}\left[y_{3}-v_{t, t+l_{2}-1}\right]-v_{t+l_{2}, t+l_{2}+l_{1}}^{(n)}, & y_{3}-v_{t, t+l_{2}-1}<y_{1}+y_{2}\end{cases}
$$


is the actual inventory position of retailer $n$ at the end of period $t+l_{2}+l_{1}$. Now the expected transfer $T_{n}\left(y_{1}, y_{2}, y_{3}\right)$ is

$$
T_{n}\left(y_{1}, y_{2}, y_{3}\right)=\gamma\left[\tilde{H}_{n}\left(\tilde{S}_{1}, \tilde{S}_{2}, \tilde{S}_{1}+\tilde{S}_{2}\right)-\tilde{H}_{n}\left(y_{1}, y_{2}, y_{3}\right)-h_{2} \mathbb{E}\left(z_{n}\left[y_{3}-u_{l_{2}}\right]-w_{n}\right)\right],
$$

which changes the costs of the retailers and the suppliers such that firm $i$ ends up with cost function $H_{i}$. Hence, we conclude from Theorem 6.2 that the optimal base stock levels are $y_{n}=S_{n}$ and $y_{3}=S_{3}$. Therefore, also here the coordination of installations in a distribution system can be implemented in practice by considering actual costs and keeping track of demands in the past $l_{2}+l_{1}+1$ periods at both retailers.

\section{Conclusions}

In this paper coordination mechanisms for three-echelon serial and distribution systems under decentralized control are studied. Attention is paid to three-echelon systems since our game-theoretic negotiation process does not allow for an easy generalization from twoechelon to three-echelon systems. All our results remain valid for $N$-echelon serial and distribution systems, where $N>3$.

The decentralized control implies that the echelon base stock levels set by the installations need not be optimal from the perspective of the supply chain as a whole. The selfish installations act in their own self interest, which conflicts with global interests. Coordination mechanisms, one for serial and one for distribution systems, are introduced to align the interests and incentives of the installations. Both mechanisms start from the equilibrium outcome under decentralized control, which needs improvement since it is not globally optimal. In this outcome the most downstream firms incur the largest costs and therefore these will initiate negotiations with their upstream neighbor in the system with the goal of decreasing their costs.

During the negotiations a coordination mechanism is employed that is based upon two ideas: first, upstream installations should be fully compensated for cost increases due to larger base stock levels, and second, they should also receive a part of the surplus of the downstream installations. The coordination mechanism alters the costs in such a way that the global optimum is the unique Nash equilibrium of the corresponding strategic game (under a very mild condition for serial systems). This result is due to the money transfers in the mechanism, which not only reduce the cost of the upstream installations but also result in lower costs for all installations. This is an important condition for the acceptance of the mechanism by all installations.

The coordination mechanism has several nice characteristics. First, the mechanism induces the upstream installation to carry inventory since the extra costs of this inventory will be reimbursed. Second, the money transfers redistribute the costs among the installations, so the cost of the system is conservated. Finally, the mechanism is designed for implementation in systems with multiple independent firms, which are more complex than systems in which all firms belong to a single organization.

Directions for future research include the extension of these results to distribution systems with unequal lead time and holding costs for the retailers, and to asymmetric information availability in serial and distribution systems. 


\section{Proofs}

Proof of Lemma 2.1 According to the definition of $D_{N}$ we derive subsequently

$$
\begin{aligned}
D_{1}\left(y_{1}\right) & =\int_{0}^{\infty} L_{1}\left(y_{1}-u_{l_{1}}\right) \mathrm{d} F_{l_{1}}\left(u_{l_{1}}\right) \\
& =h_{1}\left(y_{1}-\left(l_{1}+1\right) \mu\right)+\left(p+h_{1}+h_{2}+h_{3}\right) \int_{y_{1}}^{\infty}\left(u_{l_{1}+1}-y_{1}\right) \mathrm{d} F_{l_{1}+1}\left(u_{l_{1}+1}\right)
\end{aligned}
$$

for a one-echelon system,

$$
\begin{aligned}
D_{2}\left(y_{1}, y_{2}\right)= & D_{1}\left(y_{1}\right)+\int_{0}^{\infty} L_{2}\left(y_{2}-u_{l_{2}}\right) \mathrm{d} F_{l_{2}}\left(u_{l_{2}}\right) \\
& +\int_{y_{2}-y_{1}}^{\infty}\left[D_{1}\left(y_{2}-u_{l_{2}}\right)-D_{1}\left(y_{1}\right)\right] \mathrm{d} F_{l_{2}}\left(u_{l_{2}}\right) \\
= & D_{1}\left(y_{1}\right)+h_{2}\left(y_{2}-\left(l_{2}+1\right) \mu\right)+\int_{y_{2}-y_{1}}^{\infty}\left[D_{1}\left(y_{2}-u_{l_{2}}\right)-D_{1}\left(y_{1}\right)\right] \mathrm{d} F_{l_{2}}\left(u_{l_{2}}\right)
\end{aligned}
$$

for a two-echelon serial system. Finally, notice that for $j \geq 2$

$$
\begin{aligned}
& C_{j-1}\left(y_{1}, \ldots, y_{j-2}, y_{j}-u_{l_{j}}\right)-C_{j-1}\left(y_{1}, \ldots, y_{j-2}, y_{j-1}\right) \\
& \quad=D_{j-1}\left(y_{1}, \ldots, y_{j-2}, y_{j}-u_{l_{j}}\right)-D_{j-1}\left(y_{1}, \ldots, y_{j-2}, y_{j-1}\right) .
\end{aligned}
$$

Using this identity, we obtain

$$
\begin{aligned}
& D_{3}\left(y_{1}, y_{2}, y_{3}\right) \\
& =D_{2}\left(y_{1}, y_{2}\right)+\int_{0}^{\infty} L_{3}\left(y_{3}-u_{l_{3}}\right) \mathrm{d} F_{l_{3}}\left(u_{l_{3}}\right) \\
& \quad+\int_{y_{3}-y_{2}}^{\infty}\left[D_{2}\left(y_{1}, y_{3}-u_{l_{3}}\right)-D_{2}\left(y_{1}, y_{2}\right)\right] \mathrm{d} F_{l_{3}}\left(u_{l_{3}}\right) \\
& \quad=D_{2}\left(y_{1}, y_{2}\right)+h_{3}\left(y_{3}-\left(l_{3}+1\right) \mu\right)+\int_{y_{3}-y_{2}}^{\infty}\left[D_{2}\left(y_{1}, y_{3}-u_{l_{3}}\right)-D_{2}\left(y_{1}, y_{2}\right)\right] \mathrm{d} F_{l_{3}}\left(u_{l_{3}}\right)
\end{aligned}
$$

for a three-echelon serial system.

Proof of Lemma 3.1 Start with $D_{3}\left(y_{1}, y_{2}, y_{3}\right)$ as formulated in Lemma 2.1:

$$
\begin{aligned}
& D_{3}\left(y_{1}, y_{2}, y_{3}\right) \\
& =D_{2}\left(y_{1}, y_{2}\right)+h_{3}\left(y_{3}-\left(l_{3}+1\right) \mu\right)+\int_{y_{3}-y_{2}}^{\infty}\left[D_{2}\left(y_{1}, y_{3}-u_{l_{3}}\right)-D_{2}\left(y_{1}, y_{2}\right)\right] \mathrm{d} F_{l_{3}}\left(u_{l_{3}}\right) \\
& =h_{3}\left(y_{3}-\left(l_{3}+1\right) \mu\right)+\int_{0}^{y_{3}-y_{2}} D_{2}\left(y_{1}, y_{2}\right) \mathrm{d} F_{l_{3}}\left(u_{l_{3}}\right)+\int_{y_{3}-y_{2}}^{\infty} D_{2}\left(y_{1}, y_{3}-u_{l_{3}}\right) \mathrm{d} F_{l_{3}}\left(u_{l_{3}}\right) \\
& =h_{3}\left(y_{3}-\left(l_{3}+1\right) \mu\right)+\int_{0}^{\infty} D_{2}\left(y_{1}, \min \left(y_{3}-u_{l_{3}}, y_{2}\right)\right) \mathrm{d} F_{l_{3}}\left(u_{l_{3}}\right) \\
& =h_{3}\left(y_{3}-\left(l_{3}+1\right) \mu\right)+\mathbb{E} D_{2}\left(y_{1}, \underline{w}_{2}\right) .
\end{aligned}
$$


Among similar lines we obtain

$$
\begin{aligned}
D_{2}\left(y_{1}, w_{2}\right) & =D_{1}\left(y_{1}\right)+h_{2}\left(w_{2}-\left(l_{2}+1\right) \mu\right)+\int_{w_{2}-y_{1}}^{\infty}\left[D_{1}\left(w_{2}-u_{l_{2}}\right)-D_{1}\left(y_{1}\right)\right] \mathrm{d} F_{l_{2}}\left(u_{l_{2}}\right) \\
& =h_{2}\left(w_{2}-\left(l_{2}+1\right) \mu\right)+\mathbb{E} D_{1}\left(\underline{w}_{1}\right),
\end{aligned}
$$

and $D_{1}\left(w_{1}\right)$ follows directly from Lemma 2.1.

Proof of Lemma 3.2 The true cost for installation 1 is

$$
\begin{aligned}
\tilde{H}_{1}\left(y_{1}, y_{2}, y_{3}\right) & =\mathbb{E} \tilde{D}_{1}\left(\underline{w}_{1}\right) \\
& =\mathbb{E}\left(D_{1}\left(\underline{w}_{1}\right)+\left(h_{2}+h_{3}\right)\left(\underline{w}_{1}-\left(l_{1}+1\right) \mu\right)\right) \\
& =\mathbb{E} D_{1}\left(\underline{w}_{1}\right)+\left(h_{2}+h_{3}\right)\left(\hat{w}_{1}-\left(l_{1}+1\right) \mu\right)
\end{aligned}
$$

where the second equality is due to (1) and $\hat{w}_{1}=\mathbb{E} \underline{w}_{1}$. The true expected cost for installation 2 is

$$
\begin{aligned}
& \tilde{H}_{2}\left(y_{1}, y_{2}, y_{3}\right) \\
& =\left(h_{2}+h_{3}\right) l_{1} \mu+\left(h_{2}+h_{3}\right) \mathbb{E} \int_{0}^{\infty} \max \left(\underline{w}_{2}-u_{l_{2}}-y_{1}, 0\right) \mathrm{d} F_{l_{2}}\left(u_{l_{2}}\right) \\
& =\left(h_{2}+h_{3}\right) l_{1} \mu+\left(h_{2}+h_{3}\right) \mathbb{E} \int_{0}^{\infty}\left(\underline{w}_{2}-u_{l_{2}}-y_{1}-\min \left(\underline{w}_{2}-u_{l_{2}}-y_{1}, 0\right)\right) \mathrm{d} F_{l_{2}}\left(u_{l_{2}}\right) \\
& =\left(h_{2}+h_{3}\right) l_{1} \mu+\left(h_{2}+h_{3}\right) \mathbb{E}\left(\underline{w}_{2}-l_{2} \mu-y_{1}-\int_{0}^{\infty}\left(\underline{w}_{1}-y_{1}\right) \mathrm{d} F_{l_{2}}\left(u_{l_{2}}\right)\right) \\
& =\left(h_{2}+h_{3}\right) l_{1} \mu+\left(h_{2}+h_{3}\right)\left(\hat{w}_{2}-l_{2} \mu-\hat{w}_{1}\right),
\end{aligned}
$$

where the third equality uses $\min \left(\underline{w}_{2}-u_{l_{2}}-y_{1}, 0\right)=\underline{w}_{1}-y_{1}$ which follows directly from the definition of $w_{1}$. Similarly one obtains $\tilde{H}_{3}\left(y_{1}, y_{2}, y_{3}\right)=h_{3} l_{2} \mu+h_{3}\left(y_{3}-l_{3} \mu-\hat{w}_{2}\right)$,

Proof of Lemma 3.3 Adding $\tilde{H}_{1}$ and $\tilde{H}_{2}$ gives

$$
\begin{aligned}
& \left(\tilde{H}_{1}+\tilde{H}_{2}\right)\left(y_{1}, y_{2}, y_{3}\right) \\
& =\mathbb{E} D_{1}\left(\underline{w}_{1}\right)+\left(h_{2}+h_{3}\right)\left(\hat{w}_{1}-\left(l_{1}+1\right) \mu\right)+\left(h_{2}+h_{3}\right) l_{1} \mu+\left(h_{2}+h_{3}\right)\left(\hat{w}_{2}-l_{2} \mu-\hat{w}_{1}\right) \\
& =\mathbb{E} D_{1}\left(\underline{w}_{1}\right)+\left(h_{2}+h_{3}\right)\left(\hat{w}_{2}-\left(l_{2}+1\right) \mu\right) \\
& =\mathbb{E} D_{2}\left(y_{1}, \underline{w}_{2}\right)+h_{3}\left(\hat{w}_{2}-\left(l_{2}+1\right) \mu\right) .
\end{aligned}
$$

The first equality is due to Lemma 3.2 and the last one follows from Lemma 3.1. Adding $\tilde{H}_{3}$ results in

$$
\begin{aligned}
& \left(\tilde{H}_{1}+\tilde{H}_{2}+\tilde{H}_{3}\right)\left(y_{1}, y_{2}, y_{3}\right) \\
& =\mathbb{E} D_{2}\left(y_{1}, \underline{w}_{2}\right)+h_{3}\left(\hat{w}_{2}-\left(l_{2}+1\right) \mu\right)+h_{3} l_{2} \mu+h_{3}\left(y_{3}-l_{3} \mu-\hat{w}_{2}\right) \\
& =\mathbb{E} D_{2}\left(y_{1}, \underline{w}_{2}\right)+h_{3}\left(y_{3}-\left(l_{3}+1\right) \mu\right) \\
& =D_{3}\left(y_{1}, y_{2}, y_{3}\right) .
\end{aligned}
$$


Again, Lemma 3.2 and Lemma 3.1 are used.

Proof of Theorem 4.1 Under $y_{3}=y_{2}$ the real order-up-to-level $w_{2}$ for installation 2 becomes $w_{2}^{\prime}=\min \left(y_{2}-u_{l_{3}}, y_{2}\right)=y_{2}-u_{l_{3}}$. This level has an expected value of $\hat{w}_{2}^{\prime}=y_{2}-l_{3} \mu$. Substituting this in (4) results in

$$
\begin{aligned}
\left(\tilde{H}_{1}+\tilde{H}_{2}\right)\left(y_{1}, y_{2}, y_{2}\right) & =\mathbb{E} D_{2}\left(y_{1}, y_{2}-u_{l_{3}}\right)+h_{3}\left(y_{2}-\left(l_{3}+l_{2}+1\right) \mu\right) \\
& =\left(h_{2}+h_{3}\right)\left(y_{2}-\left(l_{3}+l_{2}+1\right) \mu\right)+\mathbb{E} D_{1}\left(\underline{w}_{1}\right)
\end{aligned}
$$

where the second equality follows from Lemma 3.1. From the same Lemma, one can see that this expression for $\left(\tilde{H}_{1}+\tilde{H}_{2}\right)\left(y_{1}, y_{2}, y_{2}\right)$ is equal to the total cost $D_{2}\left(y_{1}, y_{2}\right)$ of a twoechelon serial system in case installation 2 has holding cost $h_{2}+h_{3}$ and lead time $l_{2}+l_{3}$ (instead of $h_{2}$ and $l_{2}$ respectively). Therefore, by Lemma 2.2, the cost $\left(\tilde{H}_{1}+\tilde{H}_{2}\right)\left(y_{1}, y_{2}, y_{2}\right)$ is minimized in $y_{1}=S_{1}$ and $y_{2}=\tilde{S}_{2}>S_{2}$. The larger lead time leads to a higher base stock level for installation 2 .

Proof of Theorem 4.2 In the optimum $\left(S_{1}, \tilde{S}_{2}, \tilde{S}_{2}\right)$, surplus-1 is positive because

$$
D_{3}\left(S_{1}, \tilde{S}_{2}, \tilde{S}_{2}\right)=\min _{y_{1}, y_{2}} D_{3}\left(y_{1}, y_{2}, y_{2}\right)<\min _{y_{1}} D_{3}\left(y_{1}, y_{1}, y_{1}\right)=D_{3}\left(\tilde{S}_{1}, \tilde{S}_{1}, \tilde{S}_{1}\right) .
$$

Furthermore,

$$
\begin{aligned}
& H_{1}^{\prime}\left(S_{1}, \tilde{S}_{2}, \tilde{S}_{2}\right)-\tilde{H}_{1}\left(\tilde{S}_{1}, \tilde{S}_{1}, \tilde{S}_{1}\right) \\
& \quad=(1-\alpha) D_{3}\left(S_{1}, \tilde{S}_{2}, \tilde{S}_{2}\right)+\alpha D_{3}\left(\tilde{S}_{1}, \tilde{S}_{1}, \tilde{S}_{1}\right)-h_{3} l_{2} \mu-\tilde{H}_{2}\left(\tilde{S}_{1}, \tilde{S}_{1}, \tilde{S}_{1}\right)-\tilde{H}_{1}\left(\tilde{S}_{1}, \tilde{S}_{1}, \tilde{S}_{1}\right) \\
& \quad=(1-\alpha) D_{3}\left(S_{1}, \tilde{S}_{2}, \tilde{S}_{2}\right)+\alpha D_{3}\left(\tilde{S}_{1}, \tilde{S}_{1}, \tilde{S}_{1}\right)-\left(\tilde{H}_{1}+\tilde{H}_{2}+\tilde{H}_{3}\right)\left(\tilde{S}_{1}, \tilde{S}_{1}, \tilde{S}_{1}\right) \\
& \quad=(1-\alpha) D_{3}\left(S_{1}, \tilde{S}_{2}, \tilde{S}_{2}\right)-(1-\alpha) D_{3}\left(\tilde{S}_{1}, \tilde{S}_{1}, \tilde{S}_{1}\right) \\
& \quad<0
\end{aligned}
$$

After compensating installation 2, installation 1 is better off than before the coordination (due to the positive surplus). For installation 2 we derive

$$
H_{2}^{\prime}\left(S_{1}, \tilde{S}_{2}, \tilde{S}_{2}\right)-\tilde{H}_{2}\left(\tilde{S}_{1}, \tilde{S}_{1}, \tilde{S}_{1}\right)=\alpha D_{3}\left(S_{1}, \tilde{S}_{2}, \tilde{S}_{2}\right)-\alpha D_{3}\left(\tilde{S}_{1}, \tilde{S}_{1}, \tilde{S}_{1}\right)<0 .
$$

The compensation leads to lower costs for installation 2. We conclude that both installations gain from the coordination.

Proof of Theorem 4.3 According to Lemma $2.2 D_{3}\left(S_{1}, y_{2}, y_{3}\right)$ is minimized in $\left(S_{1}, y_{2}, y_{3}\right)=$ $\left(S_{1}, S_{2}, S_{3}\right)$. In this minimum, surplus-2 is equal to $D_{3}\left(S_{1}, \tilde{S}_{2}, \tilde{S}_{2}\right)-D_{3}\left(S_{1}, S_{2}, S_{3}\right)$. This surplus is positive because

$$
D_{3}\left(S_{1}, S_{2}, S_{3}\right)=\min _{y_{1}, y_{2}, y_{3}} D_{3}\left(y_{1}, y_{2}, y_{3}\right)<\min _{y_{1}, y_{2}} D_{3}\left(y_{1}, y_{2}, y_{2}\right)=D_{3}\left(S_{1}, \tilde{S}_{2}, \tilde{S}_{2}\right) .
$$

where the first equality is due to Lemma 2.2. Using this we obtain

$$
\begin{aligned}
& \left(H_{1}+H_{2}\right)\left(S_{1}, S_{2}, S_{3}\right) \\
& \quad=(1-\beta) D_{3}\left(S_{1}, S_{2}, S_{3}\right)-\tilde{H}_{3}\left(S_{1}, \tilde{S}_{2}, \tilde{S}_{2}\right)+\beta D_{3}\left(S_{1}, \tilde{S}_{2}, \tilde{S}_{2}\right)
\end{aligned}
$$




$$
\begin{aligned}
& =(1-\beta) D_{3}\left(S_{1}, S_{2}, S_{3}\right)-(1-\beta) D_{3}\left(S_{1}, \tilde{S}_{2}, \tilde{S}_{2}\right)+D_{3}\left(S_{1}, \tilde{S}_{2}, \tilde{S}_{2}\right)-\tilde{H}_{3}\left(S_{1}, \tilde{S}_{2}, \tilde{S}_{2}\right) \\
& <D_{3}\left(S_{1}, \tilde{S}_{2}, \tilde{S}_{2}\right)-\tilde{H}_{3}\left(S_{1}, \tilde{S}_{2}, \tilde{S}_{2}\right) \\
& =\left(H_{1}^{\prime}+H_{2}^{\prime}\right)\left(S_{1}, \tilde{S}_{2}, \tilde{S}_{2}\right)
\end{aligned}
$$

for the installations 1 and 2 and

$$
\begin{aligned}
H_{3}\left(S_{1}, S_{2}, S_{3}\right) & =\beta D_{3}\left(S_{1}, S_{2}, S_{3}\right)+\tilde{H}_{3}\left(S_{1}, \tilde{S}_{2}, \tilde{S}_{2}\right)-\beta D_{3}\left(S_{1}, \tilde{S}_{2}, \tilde{S}_{2}\right) \\
& <\tilde{H}_{3}\left(S_{1}, \tilde{S}_{2}, \tilde{S}_{2}\right)
\end{aligned}
$$

for installation 3. Both inequalities follow from surplus-2 being positive in the minimum $\left(S_{1}, S_{2}, S_{3}\right)$

Proof of Lemma 4.4 The cost distribution results in a cost saving for installation 1 because

$$
\begin{aligned}
& H_{1}^{\prime}\left(S_{1}, S_{2}, S_{3}\right) \\
& \quad=(1-\alpha)\left(D_{3}-\tilde{H}_{3}\right)\left(S_{1}, S_{2}, S_{3}\right)+\alpha\left(D_{3}-\tilde{H}_{3}\right)\left(\tilde{S}_{1}, \tilde{S}_{1}, \tilde{S}_{1}\right)-\tilde{H}_{2}\left(\tilde{S}_{1}, \tilde{S}_{1}, \tilde{S}_{1}\right) \\
& \quad<(1-\alpha)\left(D_{3}-\tilde{H}_{3}\right)\left(S_{1}, \tilde{S}_{2}, \tilde{S}_{2}\right)+\alpha\left(D_{3}-\tilde{H}_{3}\right)\left(\tilde{S}_{1}, \tilde{S}_{1}, \tilde{S}_{1}\right)-\tilde{H}_{2}\left(\tilde{S}_{1}, \tilde{S}_{1}, \tilde{S}_{1}\right) \\
& \quad=H_{1}^{\prime}\left(S_{1}, \tilde{S}_{2}, \tilde{S}_{2}\right),
\end{aligned}
$$

where $D_{3}\left(S_{1}, S_{2}, S_{3}\right)<D_{3}\left(S_{1}, \tilde{S}_{2}, \tilde{S}_{2}\right)$ and $\tilde{H}_{3}\left(S_{1}, S_{2}, S_{3}\right)>\tilde{H}_{3}\left(S_{1}, \tilde{S}_{2}, \tilde{S}_{2}\right)$ are used. Installation 2 saves cost if

$$
H_{2}^{\prime}\left(S_{1}, S_{2}, S_{3}\right)+\text { compensation to } 3<H_{2}^{\prime}\left(S_{1}, \tilde{S}_{2}, \tilde{S}_{2}\right),
$$

or if the compensation to 3 is smaller than $H_{2}^{\prime}\left(S_{1}, \tilde{S}_{2}, \tilde{S}_{2}\right)-H_{2}^{\prime}\left(S_{1}, S_{2}, S_{3}\right)$. Concentrate on this latter difference:

$$
\begin{aligned}
& H_{2}^{\prime}\left(S_{1}, \tilde{S}_{2}, \tilde{S}_{2}\right)-H_{2}^{\prime}\left(S_{1}, S_{2}, S_{3}\right) \\
& \quad=\alpha\left(D_{3}-\tilde{H}_{3}\right)\left(S_{1}, \tilde{S}_{2}, \tilde{S}_{2}\right)-\alpha\left(D_{3}-\tilde{H}_{3}\right)\left(S_{1}, S_{2}, S_{3}\right) \\
& \quad=\alpha\left(\left(H_{1}^{\prime}+H_{2}^{\prime}\right)\left(S_{1}, \tilde{S}_{2}, \tilde{S}_{2}\right)-\left(H_{1}^{\prime}+H_{2}^{\prime}\right)\left(S_{1}, S_{2}, S_{3}\right)\right),
\end{aligned}
$$

which is larger than the compensation paid to 3 if $\alpha>\alpha$. Equation (2) is used in the final equality.

Proof of Theorem 4.5 The coordination mechanism leads to the unique choice $\left(S_{1}, S_{2}, S_{3}\right)$ of base stock levels. Furthermore, in this optimum all players have lower cost than on their own and the players 1 and 2 also have lower cost compared to the first round of negotiation if $\alpha>\underline{\alpha}$. We conclude that $\left(S_{1}, S_{2}, S_{3}\right)$ is the unique Nash equilibrium of the corresponding strategic game.

Proof of Lemma 6.1 Minimizing $H_{n}\left(y_{1}, y_{2}, y_{3}\right)$ with respect to $y_{n}$ is equivalent to minimizing

$$
\tilde{H}_{n}\left(y_{1}, y_{2}, y_{3}\right)+h_{2} \mathbb{E}\left(z_{n}\left[y_{3}-u_{l_{2}}\right]-w_{n}\right)
$$

because the other terms in $H_{n}\left(y_{1}, y_{2}, y_{3}\right)$ are constants. If we recall the definition of $\tilde{H}_{n}\left(y_{1}, y_{2}, y_{3}\right)$, this expression can be rewritten to

$$
\mathbb{E} C_{n}\left(w_{n}\right)+h_{2} \mathbb{E}\left(z_{n}\left[y_{3}-u_{l_{2}}\right]-u_{l_{1}+1}^{(n)}\right) .
$$


The second term is independent of $y_{n}$. Therefore minimizing $H_{n}\left(y_{1}, y_{2}, y_{3}\right)$ boils down to minimizing $\mathbb{E} C_{n}\left(w_{n}\right)$ with respect to $y_{n}$, where

$$
\mathbb{E} C_{n}\left(w_{n}\right)=C_{n}\left(y_{n}\right) F_{l_{2}}\left(y_{3}-\left(y_{1}+y_{2}\right)\right)+\int_{y_{3}-\left(y_{1}+y_{2}\right)}^{\infty} C_{n}\left(z_{n}\left[y_{3}-u_{l_{2}}\right]\right) \mathrm{d} F_{l_{2}}\left(u_{l_{2}}\right) .
$$

The first order condition for a minimum of $\mathbb{E} C_{n}\left(w_{n}\right)$ is

$$
C_{n}^{\prime}\left(y_{n}\right) F_{l_{2}}\left(y_{3}-\left(y_{1}+y_{2}\right)\right)-\left(C_{n}\left(y_{n}\right)-C_{n}\left(z_{n}\left[y_{1}+y_{2}\right]\right)\right) f_{l_{2}}\left(y_{3}-\left(y_{1}+y_{2}\right)\right)=0 .
$$

Due to $z_{n}\left[y_{1}+y_{2}\right]=y_{n}$ this first order condition reduces to

$$
C_{n}^{\prime}\left(y_{n}\right) F_{l_{2}}\left(y_{3}-\left(y_{1}+y_{2}\right)\right)=0 .
$$

This equality holds if $y_{n}=S_{n}$ because $S_{n}$ minimizes $C_{n}$. The second order condition for a minimum is also satisfied.

Proof of Theorem 6.3 First, consider the retailers. Denote $w_{n}$ by $w_{n}\left(y_{1}, y_{2}, y_{3}\right)$ to explicitly show the dependence on $\left(y_{1}, y_{2}, y_{3}\right)$. Due to Lemma 6.1

$$
\begin{aligned}
H_{n} & \left(S_{1}, S_{2}, S_{3}\right) \\
< & H_{n}\left(\tilde{S}_{1}, \tilde{S}_{2}, \tilde{S}_{1}+\tilde{S}_{2}\right) \\
= & (1-\gamma)\left(\tilde{H}_{n}\left(\tilde{S}_{1}, \tilde{S}_{2}, \tilde{S}_{1}+\tilde{S}_{2}\right)+h_{2} \mathbb{E}\left(z_{n}\left[\tilde{S}_{1}+\tilde{S}_{2}-u_{l_{2}}\right]-w_{n}\left(\tilde{S}_{1}, \tilde{S}_{2}, \tilde{S}_{1}+\tilde{S}_{2}\right)\right)\right) \\
& \quad+\gamma \tilde{H}_{n}\left(\tilde{S}_{1}, \tilde{S}_{2}, \tilde{S}_{1}+\tilde{S}_{2}\right) \\
= & \tilde{H}_{n}\left(\tilde{S}_{1}, \tilde{S}_{2}, \tilde{S}_{1}+\tilde{S}_{2}\right) .
\end{aligned}
$$

The last equality results from $w_{n}\left(\tilde{S}_{1}, \tilde{S}_{2}, \tilde{S}_{1}+\tilde{S}_{2}\right)=z_{n}\left[\tilde{S}_{1}+\tilde{S}_{2}-u_{l_{2}}\right]$.

Second, consider the supplier.

$$
\begin{aligned}
H_{3}\left(S_{1}, S_{2}, S_{3}\right) & =\gamma D^{(3)}\left(S_{1}, S_{2}, S_{3}\right)+\tilde{H}_{2}\left(\tilde{S}_{1}, \tilde{S}_{2}, \tilde{S}_{1}+\tilde{S}_{2}\right)-\gamma D^{(3)}\left(\tilde{S}_{1}, \tilde{S}_{2}, \tilde{S}_{1}+\tilde{S}_{2}\right) \\
& <\tilde{H}_{3}\left(\tilde{S}_{1}, \tilde{S}_{2}, \tilde{S}_{1}+\tilde{S}_{2}\right)
\end{aligned}
$$

where the inequality follows from $D^{(3)}\left(S_{1}, S_{2}, S_{3}\right)<D^{(3)}\left(\tilde{S}_{1}, \tilde{S}_{2}, \tilde{S}_{1}+\tilde{S}_{2}\right)$.

\section{References}

Axsäter, S., \& Zhang, W.-F. (1999). A joint replenishment policy for multi-echelon inventory control. International Journal of Production Economics, 59, 243-250.

Cachon, G. P. (2001). Stock wars: inventory competition in a two-echelon supply chain with multiple retailers. Operations Research, 49, 658-674.

Cachon, G. P., \& Zipkin, P. H. (1999). Competitive and cooperative inventory policies in a two-stage supply chain. Management Science, 45, 936-953.

Chen, F., Federgruen, A., \& Zheng, Y.-S. (2001). Coordination mechanisms for a distribution system with one supplier and multiple retailers. Management Science, 47, 693-708.

Clark, A. J., \& Scarf, H. (1960). Optimal policies for a multi-echelon inventory problem. Management Science, 6, 475-490.

Eppen, G., \& Schrage, L. (1981). Centralized ordering policies in a multi-warehouse system with lead times and random demand. In L. B. Schwarz (Ed.), Studies in the management sciences: Vol. 16. Multi-level production/inventory control systems: theory and practice (pp. 51-67) Amsterdam: North-Holland 
Giannoccaro, I., \& Pontrandolfo, P. (2004). Supply chain coordination by revenue sharing contracts. International Journal of Production Economics, 89, 131-139.

Gjerdrum, J., Shah, N., \& Papageorgiou, L. G. (2002). Fair transfer price and inventory holding policies in two-enterprise supply chains. European Journal of Operational Management, 143, 582-599.

Güllü, R., van Houtum, G. J., Alişan, Z., \& Erkip, N. (2003). Analysis of a decentralized supply chain under partial cooperation. Beta Working Paper Series no. 90.

Langenhoff, L. J. G., \& Zijm, W. H. M. (1990). An analytical theory of multi-echelon production/distribution systems. Stat. Neerl., 44, 149-174.

Lee, H., \& Whang, S. (1999). Decentralized multi-echelon supply chains: incentives and information. Management Science, 45, 633-640.

Osborne, M. J., \& Rubinstein, A. (1994). A course in game theory. Cambridge: MIT Press.

Özer, Ö. (2003). Replenishment strategies for distribution systems under advance demand information. Management Science, 49, 255-272.

Taylor, T. A. (2002). Supply chain coordination under channel rebates with sales effort effects. Management Science, 48, 992-1007.

Van Houtum, G. J., Inderfurth, K., \& Zijm, W. H. M. (1996). Materials coordination in stochastic multiechelon systems. European Journal of Operational Research, 95, 1-23.

Viswanathan, S., \& Piplani, R. (2001). Coordinating supply chain inventories through common replenishment epochs. European Journal of Operational Research, 129, 277-286.

Wang, H., Guo, M., \& Efstathiou, J. (2004). A game-theoretical cooperative mechanism design for a twoechelon decentralized supply chain. European Journal of Operational Research, 157, 372-388. 